\title{
Prevailing Buffalo Calf Rearing Practices and Mortality Patterns in the Operational Area of Dairy Vigyan Kendra, Gujarat
}

\author{
S.J. Jadav', Y.G. Patel ${ }^{2}$
}

10.18805/ajdfr.DR-1756

\begin{abstract}
Background: The study aimed to observe the prevailing buffalo calf rearing practices and mortality patterns in the operational area of Dairy Vigyan Kendra (DVK), Vejalpur, Gujarat, India.

Methods: Using the simple random sampling method, 240 buffalo owners from 24 villages of 6 talukas from the operational area of Dairy Vigyan Kendra were selected. The data were collected based on the interview schedule.

Result: The majority of buffalo owners had not adopted the different management practices viz., provision of milk replacer, calf starter, mineral mixture, salt, deworming agent at every month up to six months and vaccine. An overall buffalo calf mortality was observed $24.26 \%$ in the study area. There was a higher mortality rate in male calves $(45.00 \%)$ than female buffalo calves (14.58\%) because of negligence towards the male calf. The mortality rate observed was higher during the first three months of age (90.98\%) and during winter $(45.08 \%)$. A negative and significant relationship was observed between some important calf rearing practices like colostrum feeding time, providing milk replacer, calf starter, concentrate feed, mineral mixture, dewormer and vaccines to calves with female buffalo calf mortality. Participation in various animal husbandry training programs and adoption of scientific management practices to large herd size farms will be helpful to reduce female buffalo calf mortality rate at the field level.

Key words: Buffalo calves, Buffalo owners, Mortality, Pattern.
\end{abstract}

\section{INTRODUCTION}

Buffalo plays a crucial role in the Indian dairy sector, especially in the rural economy, with about $49 \%$ in milk production and $19.05 \%$ in meat production (Anonymous, 2019). Calf rearing is an essential aspect of dairy farming, which is often neglected by dairy farmers. This must be kept in mind that improved calf rearing ensures animals with better growth, health and productivity. Due to the high mortality of calves in India because of mismanagement, calf rearing should be taken upon scientific lines and economically achieved (Banerjee, 1998). Considering these facts, there is a vast scope for increased productivity through improved management practices, including calf rearing practices to get maximum profits (Singh et al., 2012). It is estimated that $20 \%$ of neonatal calf mortality can reduce net profit by $38 \%$ (Radostits et al., 2000). Very high buffalo calf mortality has been reported, particularly during the first few months of their postnatal life (Shivarudrappa et al., 2013; Shakya et al., 2017). The present study was conducted to investigate the prevailing buffalo calf rearing practices and mortality patterns in the operation area of Dairy Vigyan Kendra (DVK), Vejalpur, Anand Agricultural University, Anand.

\section{MATERIALS AND METHODS}

The study was conducted among the buffalo owners in the operational area of Dairy Vigyan Kendra (DVK), Vejalpur from August to November 2020. Eleven talukas are under the operational jurisdiction of DVK. A total of six talukas of the operational area of DVK were randomly selected for the study. Four villages were selected randomly from each taluka and ten buffalo owners were randomly selected from each
'Dairy Vigyan Kendra, SMC College of Dairy Science, Anand Agricultural University, Anand-388 110, Gujarat, India.

2Department of Livestock Production Management, College of Veterinary Science and Animal Husbandry, Anand Agricultural University, Anand-388 110, Gujarat, India.

Corresponding Author: S.J. Jadav, Dairy Vigyan Kendra, SMC College of Dairy Science, Anand Agricultural University, Anand388 110, Gujarat, India. Email: sanjay.jadav89@gmail.com

How to cite this article: Jadav, S.J. and Patel, Y.G. (2022). Prevailing Buffalo Calf Rearing Practices and Mortality Patterns in the Operational Area of Dairy Vigyan Kendra, Gujarat. Asian Journal of Dairy and Food Research. DOI: 10.18805/ajdfr.DR-1756.

Submitted: 10-06-2021 Accepted: 26-11-2021 Online: 17-01-2022

village, thus making the total sample of 240 buffalo owners from 24 villages were selected for the investigation by adopting Ex-Post-Facto research design. A standardized, well-structured pre-tested interview schedule was prepared in light of the objectives in consultation with the experts of Livestock Production Management. The buffalo calf mortality data were categorized based on age and sex group. During the study, the months were categorized into three seasons, viz. winter (November to February), summer (March to June), and monsoon (July to October). The data were collected and analyzed with suitable statistical techniques. SPSS 21 (IBM, USA) was used to analyze the collected data. The mortality rate is the ratio of the number of deaths in the year to the average total population of the year. The mortality rate has three essential elements, (a) a specifically defined 
population group- the denominator, (b) the time period and (c) the number of deaths occurring in that population group during that time period- the numerator.

$$
\begin{aligned}
& \text { Mortality rate }= \\
& \frac{\text { Number of died animal in the study area }}{\text { Total animal population in the study area }}
\end{aligned}
$$

\section{RESULTS AND DISCUSSION}

The majority of buffalo owners belonged to the middle age group with primary to secondary education level with marginal to small size of landholdings and had kept Surti and Mehsani buffalo with medium herd size. The area selected for the study is not having home tract of any specific breed. However, most farmers keep a mixed population of Surti and Mehsani buffaloes because the home tract of both these breeds is just nearer to their living area. The majority
(58.33\%) of them have not received training related to animal husbandry. They are not passionate to learn new things and have less interest in keeping livestock alone. For the breeding of buffaloes, the majority of buffalo owners $(52.92 \%)$ were using artificial insemination technique (Table 1).

A perusal of the data shown in Table 2 indicates that a cent per cent of buffalo owners remain present during the calving process. The majority of buffalo owners had adopted suckling $(99.58 \%)$, cleaned the calf immediately after birth $(88.75 \%)$, and had not used disinfectant after cutting of navel cord (87.91\%). Maousami et al. (2013) also reported a similar result with $96.00 \%$ of owners not disinfecting the navel cord after cutting. Due to cent per cent farmers' presence during calving, the majority of them used to clean the buffalo calf after calving. As owners are aware of buffalo's

\begin{tabular}{|c|c|c|}
\hline \multirow{2}{*}{ Profile of buffalo owners } & \multicolumn{2}{|c|}{ Total } \\
\hline & Frequency & Per cent \\
\hline \multicolumn{3}{|l|}{ Age } \\
\hline Young ( $\leq 35$ years) & 31 & 12.92 \\
\hline Middle-aged (36-50 Years) & 125 & 52.08 \\
\hline Old $(>50$ Years $)$ & 84 & 35.00 \\
\hline \multicolumn{3}{|l|}{ Education } \\
\hline Illiterate & 33 & 13.75 \\
\hline Primary education (up to $8^{\text {th }}$ standard) & 87 & 36.25 \\
\hline Secondary education ( $9^{\text {th }}$ to $10^{\text {th }}$ standard) & 68 & 28.33 \\
\hline Higher secondary education ( $11^{\text {th }}$ to $12^{\text {th }}$ standard) & 28 & 11.67 \\
\hline Graduate and above & 24 & 10.00 \\
\hline \multicolumn{3}{|l|}{ Landholding } \\
\hline Landless farmers & 3 & 1.25 \\
\hline Marginal farmer (Up to $1.00 \mathrm{ha}$ ) & 163 & 67.92 \\
\hline Small farmer (1.01 to $2.00 \mathrm{ha})$ & 51 & 21.25 \\
\hline Medium farmer (2.01 to 4.00 ha) & 16 & 6.66 \\
\hline Large farmer (Above $4.00 \mathrm{ha})$ & 7 & 2.92 \\
\hline \multicolumn{3}{|l|}{ Buffalo herd composition } \\
\hline Surti & 169 & 70.42 \\
\hline Mehsani & 156 & 65.00 \\
\hline Non-Descript & 131 & 54.58 \\
\hline Banni & 15 & 6.25 \\
\hline Jaffrabadi & 2 & 0.83 \\
\hline \multicolumn{3}{|l|}{ Herd Size (in Standard Animal Unit) } \\
\hline Small $(\leq 4$ SAU $)$ & 89 & 37.08 \\
\hline Medium (4.01 to $8 \mathrm{SAU})$ & 142 & 59.17 \\
\hline Large $(>8$ SAU) & 9 & 3.75 \\
\hline \multicolumn{3}{|l|}{ Training in animal husbandry } \\
\hline Training received & 100 & 41.67 \\
\hline Training not received & 140 & 58.33 \\
\hline \multicolumn{3}{|l|}{ Breeding method used in buffalo } \\
\hline Al & 127 & 52.92 \\
\hline Natural & 2 & 0.83 \\
\hline Both & 111 & 46.25 \\
\hline
\end{tabular}
powerful mothering instinct and not letting down milk in the

Table 1: Profile of buffalo owners $(n=240)$. 
Table 2: Prevailing buffalo calf rearing practice $(n=240)$.

Prevailing practices

Management

Owner's presence during calving Frequency

Per cent

Clean the calf immediately after birth

100.00

Cut the navel cord of calf

Cut navel cord with a sharp object

Cut navel cord with a sterilized sharp object

88.75

32.91

79

32.08

Which disinfectant use after cuting of nave cc

el cord?
A. Tincture of iodine
B. Other (Neem or Turmeric paste)

1.67

10.42

C. No disinfectant use

87.91

Calf rearing method
A. Suckling
B. Weaning method

\section{Feeding}

Feeding of colostrum to the calf

Time of first colostrum feeding
A. Within one hour of birth
B. One to four hours of birth
C. After dropping of placenta

48.75

Provide milk to the calf

28.75

Quantity of milk provides to calf

98.75
A. One quarter
B. Two quarter
C. Ad lib
D. As per body weight
Milk feeding up to age

A. One month

B. Two months

C. Three months

D. More than three months

Providing milk replacer to calf

Providing calf starter to calf

Providing concentrate feed to calf

Started giving concentrate after attaining the age of
A. One month
B. Two Months
C. Three months
D. Four months

27.50

39.17

14.17

7.08

Started giving green fodder after attaining the age of
A. One month
B. Two Months

Providing mineral mixture to calf

Providing salt to calf

79.17

20.83

32.50

17.50

\section{Housing of calf}

Housing facility
A. Separate
B. Same place with a dam in one side
Protection against inclement weather

A. Winter (Heating facility, Provide gunny bag) 
Prevailing Buffalo Calf Rearing Practices and Mortality Patterns in the Operational Area of Dairy Vigyan Kendra, Gujarat

Table 2: Continue..

B. Summer (Shed, Normal and freshwater)

C. Monsoon (Shed)

240

210

Health

Deworming of calf

Deworming at 21 days age of the calf

Deworming at every month up to 6 months of calf

Deworming at every six months of calf

Source of dewormer

A. Co-operative dairy

B. Govt. Vet. Dispensary

C. Medical store

D. Private Veterinarian /Para vet.

Use dewormers rotationally

Vaccination of calf

Which vaccines are given to your calf?
A. Brucellosis
B. FMD
C. HS
Type of treatment
A. Called a vet. or para-vets immediately when calf fell sick
B. Used indigenous medicines then a vet. was called
C. Never called a veterinarian

100.00

87.50

84.58

55.42

18.75

81.67

84.17

7.50

10.83

9.58

22.08

62.08

1.25

62.08

32.50

78

75.00

24.58

0.42 absence of their young ones, they have adopted suckling. It was observed that only $32.91 \%$ of farmers had cut the navel cord of buffalo calves. In their study, Tiwari et al. (2007) observed that none of the farmers were used to cut the navel cord of the newborn.

The majority of buffalo owners had provided colostrum $(99.58 \%)$, milk $(98.75 \%)$ and concentrate feed $(87.92 \%)$ to their calf. More than one-fifth of the buffalo owners provided colostrum within one hour of calf birth (22.50\%). A similar result related to the present study was reported by Mahla et al. (2015). Contrary to this, Tiwari et al., (2007) observed that the majority $(87.80 \%)$ of the farmers had supplied colostrum after expulsion of placenta. Late supplementation of colostrum by the buffalo owner is mainly due to a lack of awareness about scientific animal husbandry practices. About $27.08 \%$ and $23.75 \%$ of buffalo owners had provided calf starter and milk replacer to their calf, respectively. The majority of buffalo owners had used deworming agents for their calves $(84.58 \%)$ but not maintained regularity as per scientific recommendation. The majority of the buffalo owners knew the effect of deworming on calves. They used deworming agents to calves initially but did not follow the standard deworming schedule.

Similarly, Tiwari et al. (2007) also observed lacunae in the regular provision of deworming agents to the calves. More than half of the buffalo owners had given FMD vaccine to their buffalo calves, while vaccination for Hemorrhagic Septicemia and Brucellosis was observed very low, respectively. None of them had given Anthrax and $B Q$ vaccines to their buffalo calves.
Data in Table 3 indicated that the buffalo calf mortality rate was observed $45.00 \%$ and $14.58 \%$ in male and female buffalo calves, respectively with an average of $24.26 \%$ in the operational area of DVK, Gujarat. A similar result was obtained by Maousami et al. (2013) where they have reported an average $22.45 \%$ mortality in buffalo calves. A higher mortality rate may be due to the negligence of males. There was an overall $24.26 \%$ mortality rate observed in the buffalo calves in the study area. Shakya et al. (2017) reported that overall buffalo calf mortality in and around Jabalpur district was $42.11 \%$ which is higher compared to our study. Tiwari et al. (2007), in their study of buffalo calf health care in commercial dairy farms, had also reported $81.09 \%$ mortality which was just four times more than our study.

Most of the death in buffalo calves was observed during the first three months of age (90.98\%). Shakya et al., (2017) reported similar results with the present study. In the present study, it was found that supplementation of colostrum within one hour was very less, that may result in poor development of immunity results in higher mortality rate in the initial period of life. The buffalo calf mortality rate was found to be higher in winter $(45.08 \%)$, followed by summer $(29.51 \%)$ and monsoon (25.41\%) (Table 4). Similar results were obtained by Patil et al. (1991), who reported the highest mortality (38.29\%) during winter (November-January), followed by the monsoon season (32.5\% in June-October) and summer (29.2\% in February-May). The reason of the higher mortality rate in winter may be that in this study, it was observed that the housing practice of protecting animals from inclement weather that is for cold is very less $(67.50 \%)$ as compared 
Prevailing Buffalo Calf Rearing Practices and Mortality Patterns in the Operational Area of Dairy Vigyan Kendra, Gujarat

Table 3: Buffalo calf mortality rate.

\begin{tabular}{lccc}
\hline Sex & No. of calf born in the last year & No. of calf died in the last year & Mortality rate (Per cent) \\
\hline Male & 160 & 72 & 45.00 \\
Female & 343 & 50 & 14.58 \\
Total & 503 & 122 & 24.26 \\
\hline
\end{tabular}

Table 4: Mortality pattern of buffalo calves in different age groups and seasons.

\begin{tabular}{|c|c|c|c|c|c|c|}
\hline \multirow{2}{*}{ Age/ season } & \multicolumn{3}{|c|}{ No. of calves died } & \multicolumn{3}{|c|}{ Per cent of total calf died } \\
\hline & Male & Female & Total & Male & Female & Total \\
\hline Birth to 3 months & 70 & 41 & 111 & 97.22 & 82.00 & 90.98 \\
\hline 3.01 to 6 months & 2 & 6 & 8 & 2.78 & 12.00 & 6.56 \\
\hline More than 6 months & 0 & 3 & 3 & 0.00 & 6.00 & 2.46 \\
\hline Total & 72 & 50 & 122 & 100.00 & 100.00 & 100.000 \\
\hline Winter & 30 & 25 & 55 & 41.67 & 50.00 & 45.08 \\
\hline Summer & 17 & 19 & 36 & 23.61 & 38.00 & 29.51 \\
\hline Monsoon & 25 & 6 & 31 & 34.72 & 12.00 & 25.41 \\
\hline Total & 72 & 50 & 122 & 100.00 & 100.00 & 100.00 \\
\hline
\end{tabular}

Table 5: Correlation between the profile of buffalo owners and health management practices with female buffalo calf mortality $(n=240)$.

\begin{tabular}{lc}
\hline Variables/ health management practices & $r$ value \\
\hline Age & $0.000^{\mathrm{NS}}$ \\
Education & $-0.079^{\mathrm{NS}}$ \\
Landholding & $0.054^{\mathrm{NS}}$ \\
Herd size & $0.283^{* *}$ \\
Training in animal husbandry & $-0.163^{*}$ \\
Clean the calf immediately after birth & $-0.110^{\mathrm{NS}}$ \\
Cut the navel cord of calf & $-0.032^{\mathrm{NS}}$ \\
Feeding of colostrum to the calf & $0.033^{\mathrm{NS}}$ \\
Time of colostrum feeding & $-0.185^{* *}$ \\
Provide milk to the calf & $-0.035^{\mathrm{NS}}$ \\
Providing milk replacer to calf & $-0.286^{* *}$ \\
Providing calf starter to calf & $-0.151^{*}$ \\
Providing concentrate feed to calf & $-0.313^{* *}$ \\
Providing mineral mixture to calf & $-0.203^{* *}$ \\
Providing salt to calf & $-0.074^{\mathrm{NS}}$ \\
Bedding facility & $0.010^{\mathrm{NS}}$ \\
Deworming of calf & $-0.406^{* *}$ \\
Vaccination of calf & $-0.233^{* *}$ \\
\hline$* *=$ Significant at 0.01 level; ${ }^{*}=$ Significant at 0.05 level; ${ }^{\mathrm{NS}}=\mathrm{Non}-$ \\
significant. &
\end{tabular}

to two other seasons $(100 \%$ for summer and $87.50 \%$ monsoon). The increased mortality rate during the cold season might be attributed to environmental stress associated with cold inclement weather wherein sudden climatic changes make calves prone to conditions like pneumonia and diarrhoea. High relative humidity and less bright hours lead to unhygienic calf sheds and wet beddings that make young calves more susceptible to infections (Yadav et al. 2019).
Table 5 revealed that the correlation between buffalo owners' received training in animal husbandry with female buffalo calves mortality was found negative and significant. Awareness and knowledge gained by the buffalo owners in training are helping them to raise their buffalo calves effectively. There was a positive and significant relationship between herd size and female buffalo calves mortality. This may be due to the larger herd size. Higher calf mortality with increase in herd size in commercial dairy farms was reported by Sreedhar and Sreenivas, (2015). Higher calf mortality in the larger herd may be associated with a larger group size of calves resulted in lesser time spent per calf or more opportunity for pathogen exchange, while improved management and care in the small herd may improve survival rate (Zucali et al. 2013; Seppä-Lassila et al. 2016). A major reason of urban dairy farm mortality was the parasitic infestation in the calves due to which their health deteriorated and they often died (Sharma and Mishra, 1987). There was a negative and significant relationship between colostrum feeding time, providing milk replacer, calf starter, concentrate feed, mineral mixture, dewormer, and vaccines to calves with female buffalo calf mortality (Table 5). The risk of calf mortality increases drastically with delay in colostrum feeding (Zucali et al. 2013) due to inadequate passive transfer of immunoglobulin through the gut, which may subsequently suppress the disease resistance capacity of calves (Godden, 2008). Pal et al. (2016) observed 79-85 percent reduction in calf mortality under field conditions when deworming was practiced from 1-2 weeks after birth. There was a negative and non-significant correlation between cleaning the calf immediately after birth, cutting the navel cord, provide milk and salt to the calf with female buffalo calf mortality. Some of the animal health management practices like providing milk, earlier colostrum feeding, milk replacer, calf starter, concentrate feed, mineral mixture and salt, deworming and 
vaccination, cleaning the calf immediately after birth and cutting the navel cord to calves was associated with decrease the female buffalo calf mortality (Table 5).

\section{CONCLUSION}

The majority of buffalo owners had not adopted the practices of providing milk replacer, calf starter, mineral mixture, salt, dewormer at every month up to six months and vaccine of HS, Brucellosis, Anthrax and BQ. Buffalo calf mortality was observed 45.00 and 14.58 per cent in male and female buffalo calves, respectively. Overall, the buffalo calf mortality rate was $24.26 \%$, with a higher mortality rate $(90.98 \%$ ) during the initial age (first three months) in the operational area of DVK. The training programme should be organized on scientific buffalo calf rearing practices and proper management practices to large herd size farms for reducing calf mortality rate at the field level. Some of the animal health management practices like providing milk, earlier colostrum feeding, milk replacer, calf starter, concentrate feed, mineral mixture and salt, deworming and vaccination, cleaning the calf immediately after birth and cutting the navel cord to calves which can reduce the female buffalo calf mortality in the field level.

\section{REFERENCES}

Anonymous (2019). Basic Animal Husbandry Statistics. Department of animal husbandry and dairying. Ministry of fisheries, animal husbandry and dairying. Government of India.

Banerjee, G.C. (1998). A Text Book of Animal Husbandry, $8^{\text {th }}$ Edn. Oxford and IBM Publishing Co. Pvt. Ltd., New Delhi. pp. 742.

Godden, S. (2008). Colostrum management for dairy calves. Veterinary Clinics of North America: Food Animal Practice. 24: 19-39.

Mahla, V., Choudhary, V.K., Saharan, J.S., Yadav, M.L., Kumar, S. and Choudhary, S. (2015). Study about socio-economic status and calf rearing management practices adopted by cattle keepers of Western Rajasthan, India. Indian Journal of Agricultural Research. 49(2): 189-92.

Maousami, Singh, B.P., Kumar, R., Kumar, V. and Dohare, A. (2013). Analysis of buffalo calf management practices followed by buffalo owners. Journal of Animal Science Advances. 3(3): 129-33.
Pal, S.S., Sharma, I. and Fareeda. (2016). Clinical importance of scheduled deworming in buffalo calves. Intas Polivet. 17(1): 85-87.

Patil, N.A., Mallikarjunappa, S., Kumar, S.P. and Bhat, A.R.S. (1991). Comparative study on calf mortality in Jersey crossbred and Surti buffalo calves. Indian Journal of Dairy Science. 44: 526-528.

Radostits, O.M., Gay, C.C., Blood, D.C. and Hinchcliff, K.W. (2000). Bovine Mastitis: In: Veterinary Medicine A Textbook of the Diseases of Cattle, Sheep, Pigs, Goats and Horses, $9^{\text {th }}$ Edn. W.B. Saunders Company Ltd., London. pp. 603-87.

Seppä-Lassila, L., Sarjokari, K., Hovinen, M., Soveri, T. and Norring, M. (2016). Management factors associated with mortality of dairy calves in Finland: A cross sectional study. The Veterinary Journal. 216: 164-67.

Shakya, A., Roy, B. and Baghel, R.P.S. (2017). Studies on buffalo calf mortality in Jabalpur district of Madhya Pradesh. Buffalo Bulletin. 36(3): 521-24.

Sharma, M.C. and Mishra, R.R. (1987). Livestock Health and Management. Khanna Publishers, New Delhi.

Shivarudrappa, B., Reddy, G.S., Jyoti, S. and Bhagat, R.L. (2013). Assessment of buffalo calves mortality in west Godavari district of Andhra Pradesh. Open Access Scientific Reports. 2(4): 1-3.

Singh, S.K., Agarwal, S.B. and Chandel, B S. (2012). Resource use efficiency in buffalo milk production in Varanasi district of Uttar Pradesh, India. Journal of Dairying, Foods and Home Sciences. 31: 259-63.

Sreedhar, S. and Sreenivas, D. (2015). A study on calf mortality and managemental practices in commercial dairy farms. Livestock Research International. 3(4): 94-98.

Tiwari, R., Sharma, M.C. and Singh, B.P. (2007). Buffalo calf health care in commercial dairy farms: A field study in Uttar Pradesh (India). Livestock Research for Rural Development. 19(3): 62-64.

Yadav, S., Boora, A., Singh, K.P. and Singh, I. (2019). A study of pattern in calf mortality at an organized murrah buffalo herd in India: A 24 year review. Buffalo Bulletin. 38(2): 237-48.

Zucali, M., Bava, L., Tamburini, A., Guerci, M. and Sandrucci, A. (2013). Management risk factors for calf mortality in intensive Italian dairy farms. Italian Journal of Animal Science. 12(e26): 162-66. 